\title{
Retrospective distribution of Trypanosoma cruzi I genotypes in Colombia
}

\author{
Cielo M León ${ }^{1,2}$, Carolina Hernández ${ }^{1,2}$, Marleny Montilla ${ }^{3}$, Juan David Ramírez²/+ \\ ${ }^{1}$ Red Chagas Colombia ${ }^{3}$ Grupo de Parasitología, Instituto Nacional de Salud, Bogotá, Colombia \\ ${ }^{2}$ Grupo de Investigaciones Microbiológicas, Facultad de Ciencias Naturales y Matemáticas, Universidad del Rosario, Bogotá, Colombia
}

\begin{abstract}
Trypanosoma cruzi is the aetiological agent of Chagas disease, which affects approximately eight million people in the Americas. This parasite exhibits genetic variability, with at least six discrete typing units broadly distributed in the American continent. T. cruzi I (TCI) shows remarkable genetic diversity; a genotype linked to human infections and a domestic cycle of transmission have recently been identified, hence, this strain was named TcI Dom. $_{\text {. The aim of }}$ this work was to describe the spatiotemporal distribution of TcI subpopulations across humans, insect vectors and mammalian reservoirs in Colombia by means of molecular typing targeting the spliced leader intergenic region of mini-exon gene. We analysed 101 TCI isolates and observed a distribution of sylvatic TcI in $70 \%$ and TcI ${ }_{\text {Dom }}$ in $30 \%$. In humans, the ratio was sylvatic TCI in $60 \%$ and $T_{C} I_{\text {Dom }}$ in $40 \%$. In mammal reservoirs, the distribution corresponded to sylvatic TCI in $96 \%$ and $T C I_{\text {Dom }}$ in 4\%. Among insect vectors, sylvatic TCI was observed in $48 \%$ and $T c I_{\text {Dom }}$ in $52 \%$. In conclusion, the circulation of TCI $I_{\text {Dom }}$ is emerging in Colombia and this genotype is still adapting to the domestic cycle of transmission. The epidemiological and clinical implications of these findings are discussed herein.
\end{abstract}

Key words: Chagas disease - genotypes - domestic cycle - sylvatic cycle

Chagas disease is caused by the kinetoplastid parasite Trypanosoma cruzi. This pathogen is mainly transmitted by the faeces of infected triatomine insects from the Reduviidae family. The disease is considered undertreated and is a serious public health problem in Latin America (Teixeira et al. 2006). There are 16-18 million people worldwide infected with this parasite, 50,000 of whom die every year. In 2005, 1,200 new cases were detected in endemic countries of the Americas (OMS 2008). Colombia has an estimated prevalence between $700,000-1,200,000$ and $8.000,000$ are at risk of acquiring the infection according to the geographical distribution of the insect vector species (INS 2012).

T. cruzi exhibits broad intraspecific genetic diversity and is classified into six discrete typing units (DTUs) identified as TcI-TcVI (Zingales et al. 2009, 2012). TcI presents the broadest geographical distribution, which covers the southern United States of America to northern Argentina and Chile. This DTU can be found in the sylvatic and domestic transmission cycles (Añez et al. 2004, Guhl \& Ramírez 2011, Zingales et al. 2012). This near-clade exhibits tremendous genetic diversity based on initial studies of the spliced leader intergenic region of mini-exon gene (SL-IR), which have subdivided TcI into genotypes (TcIa-TcIe) associated with different trans-

doi: 10.1590/0074-02760140402

Financial support: COLCIENCIAS, Red Chagas (380-2011/5014-537-30398)

+ Corresponding author: juand.ramirez@urosario.edu.co

Received 30 October 2014

Accepted 25 February 2015 mission cycles (Herrera et al. 2009, Cura et al. 2010). Furthermore, the use of microsatellite markers has demonstrated the emergence of a domestic genotype in Venezuela, which was previously called $\mathrm{Ven}_{\text {Dom }}$ (Llewellyn et al. 2009). Similarly, the use of ribosomal and mitochondrial markers has suggested the existence of genotypes associated with the domestic and sylvatic cycles of transmission (Ramírez et al. 2012a, b). Recent phylogenetic studies based on the nuclear and mitochondrial genomes of TcI populations have identified an emerging clade henceforth called $\mathrm{TcI}_{\mathrm{Dom}}$, which has been observed from Central America to South America due to human migration and is associated with domestic cycles of transmission. Human infection is a reflection of the adaptation of this genotype to human populations (Ramírez et al. 2012c, Zumaya-Estrada et al. 2012, Segovia et al. 2013).

Several studies have described the occurrence of $\mathrm{TcI}$ in domestic and sylvatic cycles of transmission, including its presence in patients with Chagas disease in Colombia (Zafra et al. 2008, 2011, Mantilla et al. 2010, Ramírez et al. 2010). These studies have identified the presence of sylvatic TcI as the causative agent for oral outbreaks of Chagas disease, suggesting the possibility that this type of parasite invades and infects human pantries (Ramírez et al. 2013a). Likewise, TcI has been identified in populations infecting domestic cycle vectors, as in the case of Triatoma infestans in Argentina and Paraguay; in the peridomestic cycle, as observed for $T$. infestans in Paraguay and in the sylvatic cycle, among Rhodnius neglectus and Rhodnius nasutus in Brazil and Mepraia spinolai/gajardoi in Chile (Cura et al. 2010). In Colombia, we have found the presence of TcI in Rhodnius prolixus, Panstrongylus geniculatus, Triatoma dimidiata, Rhodnius pallescens, Rhodnius robustus, Rhodnius colombiensis, Triatoma maculata and Triatoma venosa, as well as in sylvatic reservoirs such 
as Didelphis marsupialis, Dasypus novemcintus, Rattus rattus, Rhynchonycteris naso, Tamandua tetradactyla and Canis familiaris (Guhl \& Ramírez 2013, Ramírez et al. 2013b). However, most studies have not yet identified TcI subpopulations circulating within these hosts.

Understanding the genetic variability of $T$. cruzi is a tool to understand the dynamics of transmission and the severity of some symptoms in the acute and chronic phases of disease (Falla et al. 2009). Recently, we have determined the biological properties of $\mathrm{TcI}_{\mathrm{Dom}}$ compared to sylvatic TcI strains; this study showed that $\mathrm{TcI}_{\text {Dom }}$ strains cause less parasitaemia than sylvatic TcI strains and concluded that $\mathrm{TcI}_{\text {Dom }}$ strains have a low rate of tissue invasion, while sylvatic TcI strains have a high rate of tissue invasion, suggesting the importance of these sympatric genotypes (Cruz et al. 2015). Therefore, the objective of this study was to retrospectively detect $\mathrm{TcI}_{\text {Dom }}$ and sylvatic TcI strains using specific primers that amplify SL-IR from vectors, reservoirs and humans isolates from different regions of Colombia between 1984-2012.

\section{SUBJECTS, MATERIALS AND METHODS}

Study areas and ethics statement - T. cruzi isolates from humans, triatomine bugs and mammalian reservoirs from 19 departments (Amazonas, Arauca, Boyacá, Bolívar, Caquetá, Caldas, Casanare, Cesar, Cundinamarca, Guainía, Guajira, Huila, Magdalena, Meta, Norte de Santander, Putumayo, Santander, Tolima and Vaupes) in Colombia reported as having high, medium and low endemicity (Guhl \& Vallejo 1999), were obtained from a cryobank as part of the epidemiological surveillance of Chagas disease in the country by the National Institute of Health in Colombia from 1984-2012. The sampling areas were at altitudes ranging from $0-2,100 \mathrm{~m}$ above sea level, including a wide range of different ecotopes from savannah to mountains. Triatomines ( $R$. robustus, $R$. colombiensis, Rhodnius pictipes, $R$. prolixus, T. venosa, T. dimidiata, T. maculata and P. geniculatus) and mammals (D. marsupialis, C. familiaris, Caluromys lanatus, Oryzomys and $R$. rattus) were captured and released after blood collection at domestic (within dwellings), peridomestic (near dwellings) and sylvatic (more than 250 $\mathrm{m}$ from dwellings) locations. The blood was taken by technicians who were previously trained by veterinarians. In the collections locations, no specific permission to conduct field studies was required; the environmental ministry in Colombia allows for the collection of blood samples if the animals are not killed or considered endangered or protected. The species sampled are not endangered or protected. Regarding the domestic animals, oral informed consent was provided by the owners. The animals were anaesthetised and a blood sample of 1-2 $\mathrm{mL}$ was collected. After blood collection, the animals were released and manipulated following the international guiding principles for biomedical research involving animals, as issued by the Council for International Organizations of Medical Sciences. Trypanosomes were isolated from human patients following ethical clearance using a written informed consent approved by the National Institute of Health in Colombia.
Parasite isolation and DNA extraction - We obtained 101 isolates (45 from humans, 32 from mammalian reservoirs and 23 from insect vectors) from 19 departments in Colombia. DNA was extracted from 200- $\mu \mathrm{L}$ aliquots of the exponential phase cultures using a QIAamp DNA Isolation Kit. The DNA quality and concentration were measured at $260 \mathrm{~nm}$ and stored at $-20^{\circ} \mathrm{C}$.

Genotyping methods - The $T$. cruzi isolates were initially genotyped using the SL-IR, $24 \mathrm{~S} \alpha$ and $18 \mathrm{~S}$ regions to detect TcI. We used the SL-IR region to discriminate $\mathrm{TcI}_{\text {Dom }}$ genotype and TcI sylvatic isolates. The polymerase chain reaction (PCR) reaction was performed in a final volume of $20 \mu \mathrm{L}$, which contained $2 \mu \mathrm{L}$ of $10 \mathrm{X}$ reaction buffer (Invitrogen), $0.16 \mu \mathrm{L}$ of a deoxynucleotide triphosphate mix, $0.6 \mu \mathrm{L}$ of $\mathrm{MgCl}_{2}, 1 \mu \mathrm{L}$ of each primer (1Am: 5'-TGTGTGTGTATGTATGTG-3'; 1B: 5'-CGGAGCGGTGTGTGCAG-3'), $0.1 \mu \mathrm{L}$ of Taq DNA polymerase (Invitrogen) and $5 \mu \mathrm{L}$ of DNA (Villa et al. 2013). The thermal profile consisted of an initial denaturation at $94^{\circ} \mathrm{C}$ for 4 min followed by 35 cycles at $94^{\circ} \mathrm{C}$ for $30 \mathrm{~s}, 20 \mathrm{~s}$ at $55^{\circ} \mathrm{C}$ and $30 \mathrm{~s}$ at $72^{\circ} \mathrm{C}$ with a final extension at $72^{\circ} \mathrm{C}$ for $10 \mathrm{~min}$. To determine the size of the band, the amplification products were submitted to gel electrophoresis in a $2 \%$ agarose gel using as controls reference strains $\mathrm{MHOM} / \mathrm{CO} / 01 / \mathrm{DA}\left(\mathrm{TcI}_{\mathrm{Dom}}\right)$ and $\mathrm{MHOM} /$ $\mathrm{CO} / 10 / \mathrm{GC}$ (sylvatic TcI) and the images were analysed on a transilluminator. To determine the congruence for the correct assignment of $\mathrm{TcI}_{\mathrm{Dom}}$ between SL-IR and mitochondrial alleles (as previously determined), 40 strains were analysed by 10 multilocus sequence typing (MLST) mitochondrial markers, as reported elsewhere (Messenger et al. 2012).

\section{RESULTS}

We conducted retrospective discrimination for 45 isolates from humans, 32 isolates from reservoirs and 24 isolates from triatomines originating in 19 departments of Colombia from 1984-2012. The DNA bands obtained from the amplification products were 231 and $450 \mathrm{bp}$ for $\mathrm{TcI}_{\mathrm{Dom}}$ isolates and sylvatic TcI, respectively (Fig. 1). In a blinded manner, we compared the congruence of

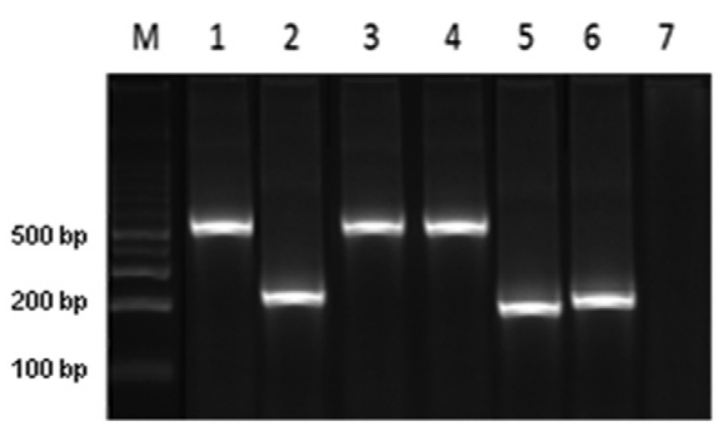

Fig. 1: TcI $_{\text {Dom }}$ strains were identified by amplying a 231 bp fragment and sylvatic TcI strains were identified by amplifying a 450-550 bp fragment. M: $100 \mathrm{bp}$ ladder; 1: MHOM/CO/10/GC strain; 2: MHOM/ CO/01/DA; 3: MHOM/CO/94/EA; 4: MHOM/CO/87/R12; 5: MHOM/ $\mathrm{CO} / 00 /$ Coyaima; 6: MHOM/CO/11/HV; 7: negative control. 


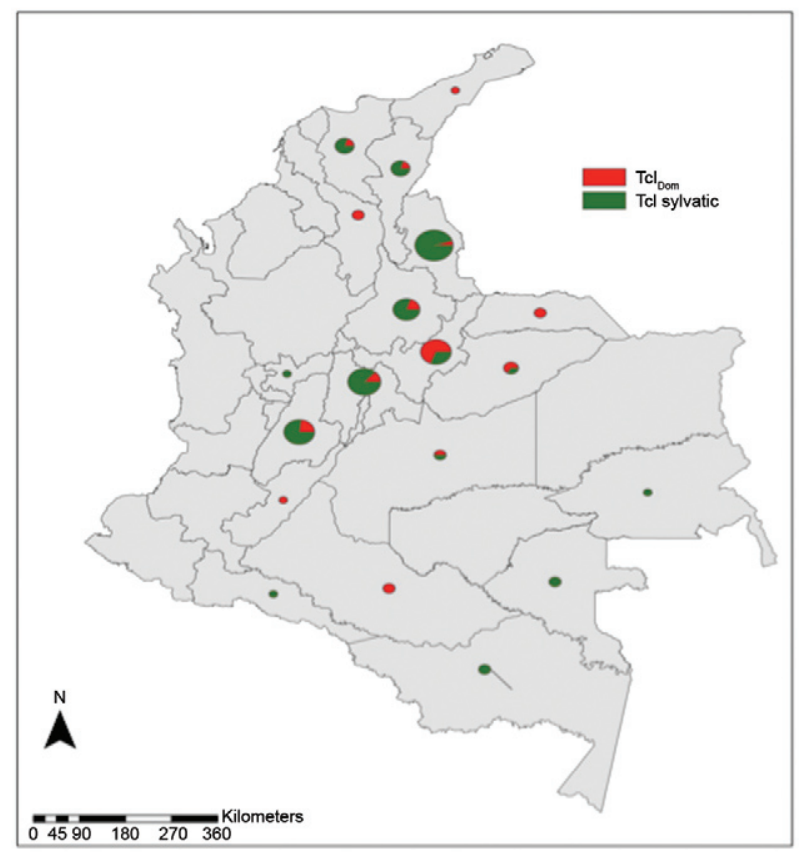

Fig. 2: geographical distribution of $\mathrm{TcI}_{\text {Dom }}$ genotype and sylvatic TcI isolates detected in the 101 isolates analysed.

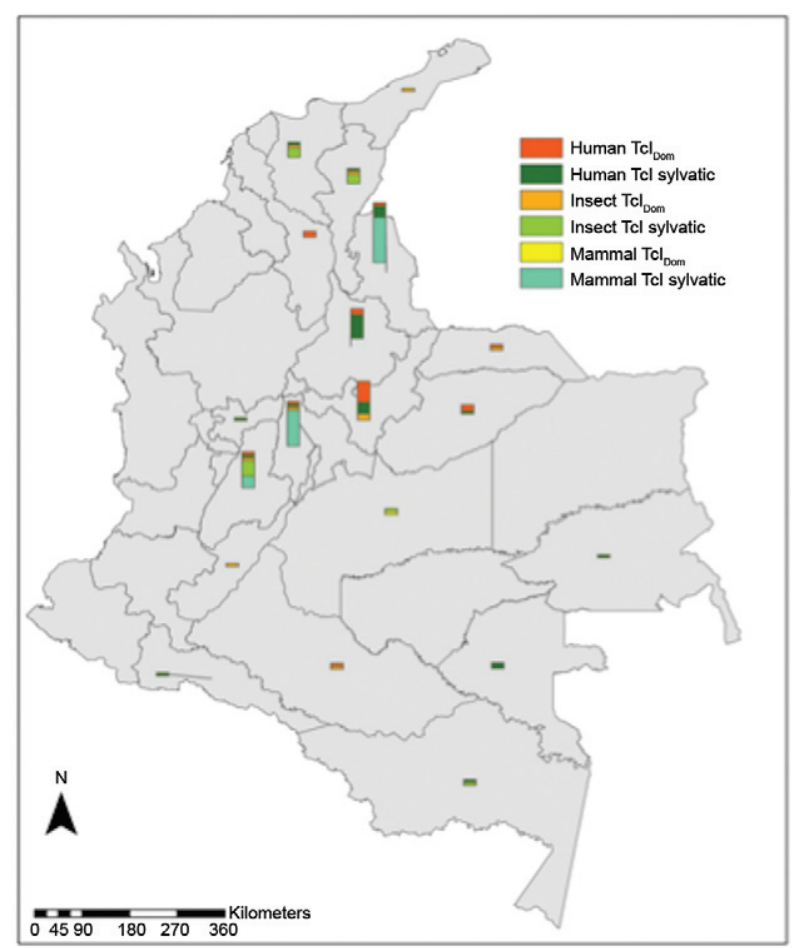

Fig. 3: biological distribution of $\mathrm{TcI}_{\mathrm{Dom}}$ genotype and sylvatic $\mathrm{TcI}$ isolates detected in the 101 isolates analysed.

SL-IR and mitochondrial MLST (mtMLST) for detecting $\mathrm{TcI}_{\text {Dom }}$ and were able to detect complete congruence between domestic TcI (SL-IR) and mitochondrial alleles by means of MLST. A higher frequency of TcI sylvatic isolates $(70 \%)$ was observed, followed by $\operatorname{TcI}_{\mathrm{Dom}}(30 \%)$ across the 101 isolates. Regarding the geographical distribution, the departments with a greater number of sylvatic TcI isolates were Norte de Santander and Cundinamarca; for the case of $\mathrm{TcI}_{\mathrm{Dom}}$, Boyacá showed the highest prevalence for this genotype (Fig. 2, Table).

Regarding the discrimination of sylvatic $\mathrm{TcI}$ and $\mathrm{TcI}_{\mathrm{Dom}}$ in human isolates, we observed a predominance of sylvatic TcI $(60 \%)$. Moreover, those isolates obtained from congenital transmission cases were typed as $\mathrm{TcI}_{\text {Dom }}$ $(40 \%)$. We also analysed 32 isolates from mammal reservoirs, including C. lanatus, C. familiaris, D. marsupialis, Oryzomys and $R$. rattus, observing the predominance of sylvatic TcI with the exception of $C$. familiaris, which was typed as $\mathrm{TcI}_{\mathrm{Dom}}$. To discriminate $\mathrm{TcI}$ genotypes among the insects, we analysed 24 isolates from $P$. geniculatus, $R$. colombiensis, $R$. pictipes, $R$. prolixus, $R$. robustus, T. dimidiata, T. maculata and T. venosa, where we detected a similar frequency: sylvatic TcI $(48 \%)$ and $\mathrm{TcI}_{\text {DoM }}(52 \%)$ (Fig. 3, Table). The domestic insect vectors, such as $R$. prolixus and $T$. dimidiata, were infected with $\mathrm{TcI}_{\mathrm{Dom}}$; furthermore, three isolates from $P$. geniculatus, $R$. robustus and $T$. venosa (sylvatic insect vectors) were found to be infected with the domestic genotype. Fig. 3 shows the geographical and biological distributions of the TcI genotypes across the 101 isolates. Humans had a higher frequency of $\mathrm{TcI}_{\text {Dom }}$ in the Boyacá department; in contrast, sylvatic TcI was mainly prevalent in the Santander department. In mammal reservoirs, we observed a higher frequency of sylvatic TcI in the Norte de Santander department. Regarding the insect vectors, a greater number of isolates were typed as $\mathrm{TcI}_{\mathrm{Dom}}$ in the Tolima department (Fig. 3).

Finally, due to the recent description of the $\mathrm{TcI}_{\text {Dom }}$ genotype, this study retrospectively determined the distribution of this genotype in TcI samples collected since 1984. A predominance of sylvatic TcI isolates was observed across the timeline, but an increase in the number of $\mathrm{TcI}_{\mathrm{Dom}}$ cases was clearly identified (Fig. 4).

\section{DISCUSSION}

T. cruzi exhibits remarkable genetic diversity, comprising at least six DTUs with the recent emergence of TcBat (Marcili et al. 2009, Zingales et al. 2012, Ramírez et al. 2014). TcI is a peculiar DTU that shows extant genetic diversity, elucidated by means of distinct genetic markers such as microsatellites, nuclear and mitochondrial MLST and SL-IR (Llewellyn et al. 2009, Guhl \& Ramírez 2011, Ramírez et al. 2012b). Prior studies have suggested the cryptic subdivision of TcI into TcIa-TcIe based on SL-IR, but this nomenclature presents serious drawbacks due to the incorrect use of the term(s) "haplotypes" and "genotypes" (Herrera et al. 2007, 2009, Cura et al. 2010). However, the scientific community insists on using the SL-IR nomenclature. Herein, we conducted the first molecular epidemiology approach to report the TcI subpopulations circulating in Colombia, using a previously reported PCR assay to discriminate domestic $\left(\mathrm{TcI}_{\mathrm{Dom}}\right)$ and sylvatic TcI populations (Villa et al. 2013). 


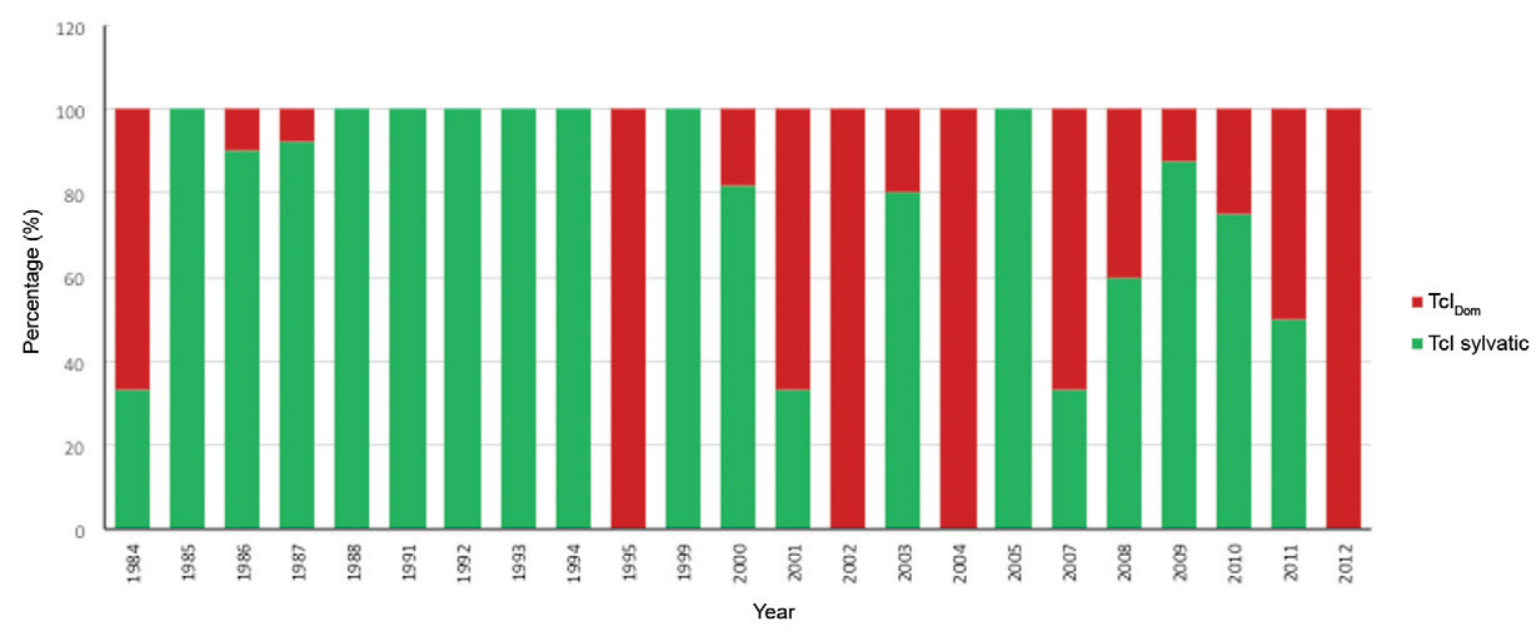

Fig. 4: temporal distribution of $\mathrm{TcI}_{\mathrm{Dom}}$ genotype and sylvatic TcI isolates detected in the 101 isolates analysed from 1984-2012.

We compared the SL-IR PCR assay for discriminating domestic and sylvatic TcI populations with the markers employed for describing this genotype (mtMLST). Our results showed complete concordance between the allelic types reported by mtMLST and designation of a domestic genotype by SL-IR. These results support the previous findings of Villa et al. (2013), who applied this PCR assay to previously characterised biological clones, confirming the potential of this assay in discriminating $\mathrm{TcI}_{\text {Dom }}$ across the Americas.

Guhl and Ramírez (2013) reported a broad study about the molecular epidemiology of T. cruzi in Colombia, but did not depict the circulating TcI genotypes across the country. Here, we conducted spatiotemporal sampling to describe the circulating populations of $\mathrm{TcI}$ in Colombia. Our results demonstrate the predominance of sylvatic TcI (70\%) populations in all the key players of the life-cycle of T. cruzi (Table). This finding is not novel because previous authors have reported the absolute occurrence of TcI sylvatic populations in the country; indeed, the study by Guhl and Ramírez (2013) shows that TcI, TcIII and TcIV (sylvatic DTUs) are commonly detected across humans, triatomines and mammal reservoirs (Guhl \& Ramírez 2013, Ramírez et al. 2013a). Regarding the TcI genotypes detected in humans, we report sylvatic $\mathrm{TcI}$ in $60 \%$ and $\mathrm{TcI}_{\mathrm{Dom}}$ in $40 \%$. This finding is interesting because of the epidemiological and clinical relevance of the higher frequency of sylvatic TcI populations in Colombia. Human Chagas disease in Colombia is mainly associated with TcI infection and some authors have tried to elucidate the effect on genetic diversity and clinical outcome. Some authors have implicated the sylvatic populations of TcI with the more severe cardiac forms of chronic Chagas disease (Mantilla et al. 2010, Ramírez et al. 2010, 2013a, Zafra et al. 2011). Additionally, a recent survey that sought to detect the TcI populations associated with oral transmission of T. cruzi implicated the sylvatic mitochondrial haplotypes (Ramírez et al. 2013a). Additionally, a recent report in a Colombian human immunodeficiency virus patient co-infected with $T$. cruzi showed a tailored histiotropism of TcI populations, reporting sylvatic $\mathrm{TcI}$ in brain tissue and domestic TcI in cardiac tissue (Hernández et al. 2014). Finally, the description of the biological features of $\mathrm{TcI}_{\mathrm{Don}}$ and sylvatic TcI in murine models suggests that sylvatic TcI causes higher histopathological damage than $\mathrm{TcI}_{\mathrm{Dom}}$ (Cruz et al. 2015). All of these advances demonstrate the important features and sympatric differences between sylvatic and domestic TcI populations. Our results show a marked prevalence of sylvatic TcI, which might explain the severity of cardiac forms of Chagas disease in Colombia.

We also evaluated the TcI genotypes circulating in mammal reservoirs. In these hosts, a major distribution of sylvatic TcI was observed, with the exception of one isolate from C. familiaris that was typed as $\mathrm{TcI}_{\mathrm{Dom}}$ (Table, Fig. 3). The mammal reservoirs surveyed were mainly sylvatic and in some cases synanthropic as D. marsupialis. This pattern also implies the zoonotic behaviour of T. cruzi transmission and highlights the reservoirs as the autochthonous vehicles of the intrusion of TcI sylvatic populations into human dwellings. Our findings are supported by those reported in Ecuador and the Argentinean Chaco, where the sylvatic reservoirs harbour mostly sylvatic TcI populations, which have been shown to arise from inbreeding and recombination with domestic populations (Ocaña-Mayorga et al. 2010, Alvarado-Otegui et al. 2012). This finding intrinsically demonstrates the importance of mammal reservoirs in the transmission dynamics of TcI, serving as a link between both ecotopes. In the case of unique $\mathrm{TcI}_{\mathrm{Dom}}$ infections in mammal reservoirs (C. familiaris), we found this infection in the Boyacá department in a domestic dwelling. A recent report of DTUs surveyed in dogs from Colombia demonstrates that dogs are important synanthropic reservoirs of T. cruzi, which also demonstrates that these animals may play a relevant role in the diversification of the T. cruzi taxon, where the domestic population can be moved back to the sylvatic ecotope (Ramírez et al. 2013b). 
TABLE

Biological distribution of Trypanosoma cruzi I (TcI) genotypes circulating in Colombian hosts (humans, mammals and triatomine bugs)

\begin{tabular}{lccc}
\hline & & \multicolumn{2}{c}{ TcI genotypes } \\
\cline { 3 - 4 } Species & & $\begin{array}{c}\text { Sylvatic TcI } \\
\mathrm{n}(\%)\end{array}$ & $\begin{array}{c}\mathrm{TcI}_{\text {Dom }} \\
\mathrm{n}(\%)\end{array}$ \\
\hline \multirow{2}{*}{ Humans } & Homo sapiens & $27(60)$ & $18(40)$ \\
& Caluromys lanatus & $1(100)$ & $0(0)$ \\
& Canis familiaris & $0(0)$ & $1(100)$ \\
& Didelphis marsupialis & $27(100)$ & $0(0)$ \\
& Onsects & $1(100)$ & $0(0)$ \\
& Rattus rattus & $2(100)$ & $0(0)$ \\
& Pastrongylus geniculatus & $0(0)$ & $1(100)$ \\
& Rhodnius colombiensis & $5(83.4)$ & $1(16.6)$ \\
& Rhodnius pictipes & $1(100)$ & $0(0)$ \\
& Rhodnius prolixus & $3(60)$ & $2(40)$ \\
& Rhodnius robustus & $0(0)$ & $1(100)$ \\
& Triatoma dimidiata & $1(33.3)$ & $2(66.6)$ \\
& Triatoma maculata & $1(100)$ & $0(0)$ \\
\hline \multirow{2}{*}{ Total } & Triatoma venosa & $0(0)$ & $1(100)$ \\
& Not classified & $2(40)$ & $3(60)$ \\
\hline & & $71(70)$ & $30(30)$ \\
\hline
\end{tabular}

Regarding the insect vectors, sylvatic TcI (48\%) and $\mathrm{TcI}_{\text {DOM }}(52 \%)$ were detected (Table, Fig. 3). This distribution was interesting in light of the high frequency of domesticated vectors in some departments, such as Boyacá, where $R$. prolixus and $T$. dimidiata are mainly adapted to the domestic foci where they harbour $\mathrm{TcI}_{\text {Dom }}$ infection. Previously, based on SL-IR genotyping, Herrera et al. (2009) reported $T$. dimidiata infected with genotypes TcIa and TcIb, which we now report as $\mathrm{TcI}_{\text {Dom }}$ (Falla et al. 2009, Herrera et al. 2009). This finding implies that the domiciliation process of triatomines has enhanced the ability of $\mathrm{TcI}_{\text {Dom }}$ to adapt to this domestic focus and be transmitted to humans. This conclusion is supported by our recent findings where $\mathrm{TcI}_{\mathrm{Dom}}$ isolates cause greater parasitaemia compared with sylvatic TcI isolates, implying that more parasites in the blood of infected individuals will increase the likelihood of infection and maintenance of this genotype in human dwellings (Cruz et al. 2015). Another notable result is that three isolates from sylvatic insect vectors ( $P$. geniculatus, $R$. robustus and $T$. venosa) were found to be infected with $\mathrm{TcI}_{\text {Dom }}$, implying that these sylvatic vectors are able to invade human dwellings and become infected with domestic populations. In contrast, $T$. venosa was captured in the Boyacá department, where there is not a clear delineation of a sylvatic focus, suggesting a peculiar domiciliation of this triatomine species. In the case of $P$. geniculatus, this insect was captured in a human dwelling, but was not domiciliated, suggesting that a clear classification of do- mestic/sylvatic status must be readdressed for this species in light of the recent implication of $P$. geniculatus in oral outbreaks in Colombia and Venezuela and reports of domiciliation (Wolff \& Castillo 2000, Carrasco et al. 2005, 2012, Alarcón de Noya et al. 2010, Ramírez et al. 2013a, Segovia et al. 2013).

Finally, we were also interested in determining the temporal variation of TcI genotypes from 1982-2012 (Fig. 4). Our results corroborate the ancient emergence of TcIDom as previously reported, showing its emergence close to the late Pleistocene (Ramírez et al. 2012c). This finding suggests the paramount importance of tracking the presence of this genotype across the players in the life-cycle of T. cruzi and also in different countries of the Americas. Recently, Zumaya-Estrada et al. (2012) tracked the dispersion and genetic diversity of this genotype, showing its low genetic diversity (proof of host adaptation) and its dispersion from the north to the south in accordance with human migration. An intensive sampling and case-control study is needed to unravel the strict associations between $\mathrm{TcI}_{\mathrm{Dom}}$ and human pathogenesis; the advent of genomics will provide more information about the biological features of this enigmatic genotype.

Here, we conducted the first retrospective molecular epidemiology study to determine the biological and geographical distribution of $\mathrm{TcI}_{\mathrm{Dom}}$ and sylvatic TcI across Colombia. We validated an easy PCR assay for discriminating these intra-DTU genotypes with a high congruence with mitochondrial alleles retrieved from MLST, as reported elsewhere (Messenger et al. 2012). We believe that depicting the real distribution of $\mathrm{TcI}_{\text {Dom }}$ is of paramount importance to unravel the history of Chagas disease and the association of this genotype with the clinical manifestations of this tropical pathology and to depict ancestral events of domiciliation. Similarly, we encourage the scientific community to avoid the use of SL-IR genotypes (TcIa-TcIe) and begin employing the $\mathrm{TcI}_{\mathrm{Dom}}$ description to prevent serious problems in genotype designation, as shown elsewhere (Muñoz-Calderón et al. 2013). Finally, we suggest to those scientists working on the molecular epidemiology of Chagas disease to determine its prevalence in other endemic countries of the Americas thanks to the rise of a single PCR assay validated here.

\section{ACKNOWLEDGEMENTS}

To Camila González, from Universidad de Los Andes, for aid in the construction of the maps. Juan David Ramírez is principal professor at Universidad del Rosario.

\section{REFERENCES}

Alarcón de Noya B, Díaz-Bello Z, Colmenares C, Ruiz R, Mauriello L, Zavala R, Suarez JA, Abate T, Naranjo L, Paiva M, Mendoza I, Acquatella H, Torres J, Noya O 2010. Large urban outbreak of orally acquired acute Chagas disease at a school in Caracas Venezuela. J Infect Dis 201: 1309-1315.

Alvarado-Otegui JA, Ceballos LA, Orozco MM, Enriquez GF, Cardinal MV, Cura C, Schijman AG, Kitron U, Gurtler RE 2012. The sylvatic transmission cycle of Trypanosoma cruzi in a rural area in the humid Chaco of Argentina. Acta Trop 124: 79-86.

Añez N, Crisante G, da Silva FM, Rojas A, Carrasco H, Umezawa ES, Stolf AM, Ramírez JL, Teixeira MM 2004. Predominance 
of lineage I among Trypanosoma cruzi isolates from Venezuelan patients with different clinical profiles of acute Chagas disease. Trop Med Int Health 9: 1319-1326.

Carrasco HJ, Segovia M, Llewellyn MS, Morocoima A, UrdanetaMorales S, Martínez C, Martínez CE, García C, Rodríguez M, Espinosa R, Alarcón de Noya B, Díaz-Bello Z, Herrera L, Fitzpatrick S, Yeo M, Miles MA, Feliciangeli MD 2012. Geographical distribution of Trypanosoma cruzi genotypes in Venezuela. PLoS Negl Trop Dis 6: e1707.

Carrasco HJ, Torrealba A, García C, Segovia M, Feliciangeli MD 2005. Risk of Trypanosoma cruzi (Kinetoplastida: Trypanosomatidae) transmission by Pastrongylus geniculatus (Hemiptera: Reduviidae) in Caracas (Metropolitan Distric) and neighboring states, Venezuela. Int J Parasitol 35: 1379-1384.

Cruz L, Vivas A, Hernández C, Montilla M, Florez C, Parra E, Ramírez JD 2015. Comparative study of the biological properties of Trypanosoma cruzi I genotypes in a murine experimental model. Infect Genet Evol 29: 110-117.

Cura CI, Mejía-Jaramillo AM, Duffy T, Burgos JM, Rodriguero M, Cardinal MV, Kjos S, Gurgel-Gonçalves R, Blanchet D, de Pablos LM, Tomasini N, da Silva A, Russomando G, Cuba CA, Aznar C, Abate T, Levin MJ, Osuna A, Gurtler RE, Diosque P, Solari A, Triana-Chávez O, Schijman AG 2010. Trypanosoma cruzi I genotypes in different geographical regions and transmission cycles based on a microsatellite motif of the intergenic spacer of spliced-leader genes. Int J Parasitol 40: 1599-1607.

Falla A, Herrera C, Fajardo A, Montilla M, Vallejo GA, Guhl F 2009. Haplotype identification within Trypanosoma cruzi I in Colombian isolates from several reservoirs, vectors and humans. Acta Trop 110: 15-21.

Guhl F, Ramírez JD 2011. Trypanosoma cruzi I diversity: towards the need of genetic subdivision? Acta Trop 119: 1-4.

Guhl F, Ramírez JD 2013. Retrospective molecular integrated epidemiology of Chagas disease in Colombia infection. Infect Genet Evol 20: 148-154.

Guhl F, Vallejo GA 1999. Interruption of Chagas disease transmission in the Andean countries: Colombia. Mem Inst Oswaldo Cruz 94 (Suppl. I): 413-415.

Hernández DC, Cucunubá ZM, Parra E, Toro G, Zambrano P, Ramírez JD 2014. Chagas disease (Trypanosoma cruzi) and HIV coinfection in Colombia. Int J Infect Dis 26: 146-148.

Herrera C, Bargues M, Falla A, Fajardo A, Montilla M, Vallejo GA, Guhl F 2009. Genetic variability and phylogenetic relationships within Trypanosoma cruzi I isolates in Colombia based on miniexon gene sequences. J Parasitol Res 2009: 897364.

Herrera C, Bargues MD, Fajardo A, Montilla M, Triana O, Vallejo GA, Guhl F 2007. Identifying four Trypanosoma cruzi I isolate haplotypes from different geographic regions in Colombia. Infect Genet Evol 7: 535-539.

INS - Instituto Nacional de Salud Colombia 2012. Informe del evento enfermedad de Chagas 2012. Available from: ins.gov.co/lineasde-accion/Subdireccion-Vigilancia/sivigila/Paginas/vigilanciarutinaria.aspx

Llewellyn MS, Miles MA, Carrasco HJ, Lewis MD, Yeo M, Vargas J, Torrico F, Diosque P, Valente V, Valente SA, Gaunt MW 2009. Genome-scale multilocus microsatellite typing of Trypanosoma cruzi discrete typing unit I reveals phylogeographic structure and specific genotypes linked to human infection. PLoS Pathog 5: e1000410.

Mantilla JC, Zafra GA, Macedo AM, González CI 2010. Mixed infection of Trypanosoma cruzi I and II in a Colombian cardiomyopathic patient. Hum Pathol 41: 610-613.
Marcili A, Lima L, Cavazzana MJ, Junqueira AC, Veludo HH, da Silva FM, Campaner M, Paiva F, Nunes VL, Teixeira MM 2009. A new genotype of Trypanosoma cruzi associated with bats evidenced by phylogenetic analyses using SSU rDNA, cytochrome $\mathrm{b}$ and histone H2B genes and genotyping based on ITS1 rDNA. Parasitology 136: 641-655.

Messenger LA, Llewellyn MS, Bhattacharyya T, Franzén O, Lewis MD, Ramírez JD, Carrasco HJ, Andersson B, Miles MA 2012. Multiple mitochondrial introgression events and heteroplasmy in Trypanosoma cruzi revealed by maxicircle MLST and next generation sequencing. PLoS Negl Trop Dis 6: e1584.

Muñoz-Calderón A, Díaz-Bello Z, Valladares B, Noya O, López MC, Alarcón de Noya B, Thomas MC 2013. Oral transmission of Chagas disease: typing of Trypanosoma cruzi from five outbreaks occurred in Venezuela shows multiclonal and common infections in patients, vectors and reservoirs. Infect Genet Evol 17: 113-122.

Ocaña-Mayorga S, Llewellyn MS, Costales JA, Miles MA, Grijalva MJ 2010. Sex, subdivision and domestic dispersal of Trypanosoma cruzi lineage I in southern Ecuador. PLoS Negl Trop Dis 4: e915.

OMS - Organización Mundial de la Salud 2008. Informe enfermedad de Chagas: control y eliminación. Available from: apps.who.int/ gb/ebwha/pdf_files/EB124/B124_17-sp.pdf.

Ramírez JD, Duque MC, Montilla M, Cucunubá ZM, Guhl F 2012a. Multilocus PCR-RFLP profiling in Trypanosoma cruzi I highlights an intraspecific genetic variation pattern. Infect Genet Evol 12: $1743-1750$.

Ramírez JD, Duque MC, Montilla M, Cucunubá ZM, Guhl F 2012b. Natural and emergent Trypanosoma cruzi I genotypes revealed by mitochondrial (Cytb) and nuclear (SSU rDNA) genetic markers. Exp Parasitol 132: 487-494.

Ramírez JD, Guhl F, Messenger L, Lewis M, Montilla M, Cucunubá Z, Miles M, Llewellyn M 2012c. Contemporary cryptic sexuality in Trypanosoma cruzi. Mol Ecol 21: 4216-4226.

Ramírez JD, Guhl F, Rendón LM, Rosas F, Marin-Neto JA, Morillo CA 2010. Chagas cardiomyopathy manifestations and Trypanosoma cruzi genotypes circulating in chronic chagasic patients. PLoS Negl Trop Dis 4: e899.

Ramírez JD, Montilla M, Cucunubá ZM, Flórez AC, Zambrano P, Guhl F 2013a. Molecular epidemiology of human oral Chagas disease outbreaks in Colombia. PLoS Negl Trop Dis 7: e2041.

Ramírez JD, Tapia G, Muñoz G, Poveda C, Rendón LM, Hincapié E, Guhl F 2014. Trypanosome species in Neotropical bats: biologi$\mathrm{cal}$, evolutionary and epidemiological implications. Infect Genet Evol 22: 250-256.

Ramírez JD, Turriago B, Tapia G, Guhl F 2013b. Understanding the role of dogs (Canis lupus familiaris) in the transmission dynamics of Trypanosoma cruzi genotypes in Colombia. Vet Parasitol 196: 216-219.

Segovia M, Carrasco HJ, Martínez CE, Messenger AN, Londoño JC, Espinosa R, Martínez C, Alfredo M, Bonfante-Cabarcas, Lewis M, Miles M, Llewellyn MS 2013. Molecular epidemiologic source tracking of orally transmitted Chagas disease, Venezuela. Emerg Infect Dis 19: 1098-1101.

Teixeira ARL, Nitz N, Guimaro M, Gomes C, Santos-Buch CA 2006. Chagas disease. Postgrad Med J 82: 788-798.

Villa LM, Guhl F, Zabala D, Ramírez JD, Urrea DA, Hernández DC, Cucunubá Z, Montilla M, Carranza JC, Rueda K, Trujillo JE, Vallejo GA 2013. The identification of two Trypanosoma cruzi I genotypes from domestic and sylvatic transmission cycles in Colombia based on a single polymerase chain reaction amplification of the splicedleader intergenic region. Mem Inst Oswaldo Cruz 108: 932-935. 
Wolff M, Castillo D 2000. Evidencias de domesticación y aspectos biológicos de Panstrongylus geniculatus (Latreille, 1811) (Hemiptera: Reduviidae). Acta Entomol Chil 24: 77-83.

Zafra G, Mantilla J, Jácome J, Macedo AM, González CI 2011. Direct analysis of genetic variability in Trypanosoma cruzi populations from tissues of Colombian chagasic patients. Hum Pathol 42: 1159-1168.

Zafra G, Mantilla JC, Valadares HM, Macedo AM, González CI 2008. Evidence of Trypanosoma cruzi II infection in Colombian chagasic patients. Parasitol Res 103: 731-734.

Zingales B, Andrade SG, Briones MRS, Campbell DA, Chiari E, Fernandes $\mathrm{O}$, Guhl F, Lages-Silva E, Macedo AM, Machado CR, Miles MA, Romanha AJ, Sturm NR, Tibayrenc M, Schijman AG
2009. A new consensus for Trypanosoma cruzi intraspecific nomenclature: second revision meeting recommends TcI to TcVI. Mem Inst Oswaldo Cruz 104: 1051-1054.

Zingales B, Miles MA, Campbell DA, Tibayrenc M, Macedo AM, Teixeira M, Schijman AG, Llewellyn M, Lages-Silva E, Machado CR, Andrade SG, Sturm N 2012. The revised Trypanosoma cruzi subspecific nomenclature: rationale, epidemiological relevance and research applications. Infect Genet Evol 12: 240-253.

Zumaya-Estrada F, Messenger LA, Lopez-Ordoñez T, Lewis M, FloresLopez CA, Martínez-Ibarra AJ, Pennington PM, Cordon-Rosales C, Carrasco HV, Segovia M, Miles MA, Llewellyn S 2012. North American import? Charting the origins of an enigmatic Trypanosoma cruzi domestic genotype. Parasit Vectors 5: 226. 